\title{
Kidney Donor Profile Index Clinical Classification
}

National Cancer Institute

\section{Source}

National Cancer Institute. Kidney Donor Profile Index Clinical Classification. NCI

Thesaurus. Code C130310.

A standardized clinician scored index created by Rao et al. in 2009 that combines ten donor factors, including demographics and medical history, to calculate the likelihood of graft failure after deceased donor kidney transplant. 